\title{
Physico-Chemical Characteristics of Biodiesel Produced via Transesterification of Commercial Vegetable (Soya Bean) Oil
}

Osarumwense, J. $\mathrm{O}^{1^{*}}$, Ebo, $N^{1}$., Omorodion, $N . T^{2}{ }^{\text {and Owie, C. I. }}{ }^{2}$

${ }^{1}$ Department of Science Laboratory Technology, University of Benin, Benin City, Nigeria

${ }^{2}$ Health Services Department, University of Benin, Benin City, Nigeria

*Email: judeosarumwense@ uniben.edu, Phone: 08023297060

\section{Article Info}

Received 04 June 2020

Revised 07 July 2020

Accepted 08 July 2020

Available online 31 August 2020

Keywords:

Biodiesel, Fossil Fuel, Free Fatty

acid, Vegetable oil, Cetane number

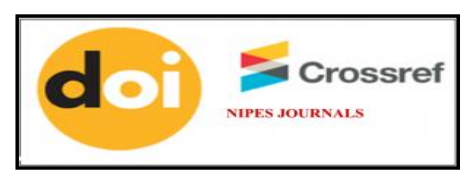

https://doi.org/10.37933/nipes/2.3.2020.19

https://nipesjournals.org.ng (c) 2020 NIPES Pub. All rights reserved

\begin{abstract}
The search for alternative and renewable fuels has increased globally in recent times owing to the increasing pressure to reduce greenhouse gas. In this work, biodiesel was produced from soya bean oil via transesterification with methanol in the presence of catalyst (sodium hydroxide). The biodiesel was purified adopting the wet purification method. The clean biodiesel was characterised by determining some physico-chemical parameters such as density, flash point, viscosity, free fatty acid (FFA), cloud point, pour point, saponification value and cetane number. The results obtained show that most of the parameters tested fell within the standard ranges as specified by the ASTM. D6751 and EN 14214. The transesterification of soya bean oil has significantly reduced the viscosity, acid value and flash point of the oil by $66.4 \%, 71.6 \%$ and $55.7 \%$ respectively. The cetane number was however on the higher range of the standard values; this is an indication that the biodiesel has a good fuel ignition property. It is therefore ascertained that the biodiesel from soya bean oil is a viable alternative to petroleum diesel, since all the quality parameters are within the standard values.
\end{abstract}

\section{Introduction}

The world, in recent times, has been confronted with increasing environmental problems owing to the huge emission of Greenhouse Gas (GHG) released from the continuous combustion of fossil fuels. This has led to the search for alternative fuels, which are environmentally friendly and sustainable [1]. Biodiesel is a renewable fuel produced from vegetable oils, and other materials such as animal fats, recycled cooking oils etc. The biodiesel manufacturing process combines oils with short chain alcohol in the presence of a catalyst to produce Fatty Alkyl Acid Esters (FAAE) which is commonly called biodiesel. Edible and non-edible vegetable oils such as rapeseed, canola, soya bean, palm, jatropha curcas and waste vegetable oils can be used mostly as the common raw materials for the production of biodiesel [2]. In addition to the depletion of petroleum fuels, gas flaring in developing countries had resulted to problems like thermal pollution, land pollution and the release of hazardous gases to the environmental [3]. The exhaust from automobile has been shown as one of the leading sources of greenhouse gas. This has resulted in a various problems such as global warming, depletion of ozone layer, rising sea levels, and significant increase in health problems as a result of inhalable particles. These worrisome trends gave rise to the development of new sources of energy, which are renewable and sustainable, with reduced tendencies for pollution. The world is witnessing an unprecedented increase in the interest and demand for biodiesel and other fuels derived from renewable biomass. Global biodiesel production was predicted to increase 


\section{J. O. Osarumwense et al. / NIPES Journal of Science and Technology Research 2(3) 2020 pp. 183-190}

to about 21.8 billion $\mathrm{dm}^{3}$ in the present decade [4]. The European Union was the highest producer in the world accounting for more than $70 \%$ of the total world production in the last decade, the United State of America was at a distance second largest producer closely followed by Brazil, and Malaysia running close behind [5]. Currently, biodiesel production efforts in African countries such as Nigeria, Tanzania, Kenya and Ghana are still very much at infancy. This work is therefore focused on the preparation and characterization of biodiesel produced from a commercial vegetable oil through transesterification reaction resulting in a biodiesel-glycerol mixture. The biodiesel was separated from the mixture, purified through wet purification method, and characterised by determining the physico-chemical properties as specified by ASTM International and European (EN) standards. The properties such as density, viscosity, flash point, cloud and pour point, acid value and free fatty acid, saponification value, iodine value, and cetane number were determined. Cetane number is a property associated with the burning of a fuel in an engine. The cetane number measures the fuel ignition quality of an engine which is actually measured by the delay in ignition. Ignition delay is a period of time that lapse between the injection and beginning of fuel combustion. Thus, a fuel with a very high cetane number has a short ignition delay and therefore, starts to burn immediately it is injected in an engine [6].

\section{Methodology}

\subsection{Collection and Preparation of Materials}

The commercial oil, soya bean oil was obtained from Uselu market in Benin City, Edo State, SouthSouth Nigeria. The reagents used in this study were of analytical grades, and were obtained from Rovet scientific limited, Benin City. The FFA value of the oil was $<0.5 \%$, therefore, pretreatment was not done. However, the oil was heated to $60^{\circ} \mathrm{C}$ for 25 minutes on a Temperature controlled Magnetic stirrer (Model TT-791), to remove any trace of water in oil. By so doing, the triglyceride hydrolysis will be avoided when mixed with alkali catalyst to avert soap formation [7].

\subsection{Production of Biodiesel}

One percent $(1 \%)$ of sodium hydroxide based on the amount of oil was mixed with a $90.5 \mathrm{~g}$ of methanol to give a 6:1 methanol-to-oil ratio. The mixture of sodium hydroxide and methanol was vigorously agitated to give a resulting solution of sodium methoxide $\left(\mathrm{NaOCH}_{3}\right)$ [7]. The sodium methoxide was mixed with $417 \mathrm{~g}$ of oil and heated to $65^{\circ} \mathrm{C}$. The mixture was continually agitated for 90 minutes in $1 \mathrm{dm}^{3}$ covered glass reactor on a hot plate magnetic stirrer [8]. At the end of the reaction time, the mixture was separated in a separating funnel into two layers (biodiesel and glycerol). The crude biodiesel was washed repeatedly with warm water in the separating funnel to remove the unreacted methanol, catalyst and other impurities. After the purification process was completed, the biodiesel was oven dried at $110^{\circ} \mathrm{C}$ for about 30 minutes to eliminate the residual water and methanol $[7,9]$. Finally the dried biodiesel was weighed. The yield was calculated using Equation (1).

$$
\% \text { Yield }=\frac{M_{B}}{M_{O}} \times 100
$$

\subsection{Charaterisation of Samples}

\subsubsection{Determination of density}

A dried and clean $25 \mathrm{~cm}^{3}$ capacity density bottle $\left(V_{L}\right)$ was weighed $\left(w_{0}\right)$, and filled with the sample, stoppered and reweighed $\left(w_{1}\right)$. The density of the sample at room temperature $\left(\approx 30^{\circ} \mathrm{C}\right)$ was taken as expressed in Equation (2) [10,11]. 
J. O. Osarumwense et al. / NIPES Journal of Science and Technology Research 2(3) 2020 pp. $183-190$

$$
D=\frac{w_{1}-w_{0}}{V_{L}}
$$

\subsubsection{Determination of viscosity}

Digital Brookfield Viscometer (model LVDV-I) was used to carry out the viscosity of the sample. A certain amount $\left(20 \mathrm{~cm}^{3}\right)$ of the sample was placed in the sample holder. A standard spindle was immersed into the sample; the temperature and speed of the viscometer were set at $40^{\circ} \mathrm{C}$ and $\quad 30$ $\mathrm{rev} / \mathrm{min}$ respectively. The viscometer was switched on and allowed to rotate for 20 minutes, and then the value of viscosity was taken on the displayed screen [12].

\subsubsection{Determination of flash point}

A closed cup Pensky-Martens flash point tester (model K16200) was employed to determine the flash point of biodiesel. An aliquot of the sample was put into the sample cup to the marked position. The sample cup was immersed into the in-built heater. Thermometer $\left(0-360^{\circ} \mathrm{C}\right)$ was then inserted into the tester. The flash point tester was switched on. The gas nozzles placed above the cup holding the sample were lit up. The flashing was observed at every $10^{\circ} \mathrm{C}$ rise in temperature. Flash point is termed to have happened when a gentle sound explosion occurred; at this point the sample was ignited. The temperature at which the explosion occurs was recorded as the flash point $[9,12]$.

\subsubsection{Determination of cloud and pour point}

The apparatus used for the determination of cloud and pour point is known as cloud and pour point bath. It consists of test jar inserted in ice chamber. The test jar was filled with the sample, and closed tightly. Thermometer was inserted, and placed into the chamber of crushed ice. At regular interval, the jar was taken out of the jacket to check for cloud without disturbing the sample. The checking was done within the time not exceeding three seconds. The cloud point was recorded when a clear amber yellow colour of the sample developed its first haziness. The same procedure was followed for the pour point determination. After the cloud point was taken, the checking continues for every $2^{\circ} \mathrm{C}$ or $3^{\circ} \mathrm{C}$ fall in temperature until the biodiesel reaches a stage where it loses the ability to flow. Then the temperature was recorded as the pour point $[13,14]$.

\subsubsection{Determination of acid value and free fatty acid (FFA)}

The acid value and FFA of the oil were determined according to equations (3) and (4) respectively $[15,16]$.

A certain weight of sample $(5 \mathrm{~g})$ was weighed and placed into a flask. $50 \mathrm{~cm}^{3}$ of a mixture of equal volume of diethyl ether and $95 \%$ ethanol was added to the flask. The content of the flask was stirred gently, and titrated with $0.1 \mathrm{~N} \mathrm{KOH}$, using some drops of phenolphthalein indicator. Equation (3) was used to compute the acid value.

$$
\text { Acid value }=\frac{T \times N_{K O H} \times 56.1}{M}
$$

The percentage FFA composition was obtained using Equation (4):

$$
\% F F A=\frac{\text { Acid value }}{2}
$$

\subsubsection{Determination of saponification value}

One gramme of sample was weighed into a flask; $25 \mathrm{~cm}^{3}$ of ethanoic potassium hydroxide $(0.1 \mathrm{~N})$ was added. The mixture was allowed to gently boil for 60 minutes on a heating mantle. The mixture was refluxed using a reflux condenser. Thereafter, the flask was cooled. Some drops of indicator (phenolphthalein) was added to the solution, titrated against $0.5 \mathrm{M}$ hydrochloric acid to end point. 
The same procedure was repeated for the blank (without the sample) [16]. The expression for saponification value $(S V)$ is given by:

$$
S V=\frac{N \times 56.1 \times\left(V_{o}-V_{1}\right)}{M}
$$

\subsubsection{Determination of iodine value}

A certain mass of sample $(0.3 \mathrm{~g})$ was weighed into a $200 \mathrm{~cm}^{3}$ flask and stoppered. Cyclohexane (10 $\mathrm{cm}^{3}$ ) was added, shaken to dissolve the sample. Using a safety pipette, Wijs reagent (iodine monochloride dissolved in acetic acid solution) was added to the flask in fume chamber. The flask was swirled vigorously. The solution was left for about 60 minutes in a dark cupboard. $20 \mathrm{~cm}^{3}$ of potassium iodide $(10 \%)$ solution plus $100 \mathrm{~cm}^{3}$ distilled water was added. The content of the flask was then titrated with $0.1 \mathrm{M}$ sodium thiosulphate solution until the disappearance of the yellow colouration. Few drops of starch $(1 \%)$ indicator were added and the solution turned blue. The titration was continued with the sodium thiosulphate in a drop wise manner until blue coloration completely disappeared. A similar procedure was carried out without the sample as the blank [10].

The values were obtained as follows:

$$
\text { Iodine value }=\frac{(B V-T V)-(1.003) \times C F}{M}
$$

\subsubsection{Determination of cetane index $(\mathrm{CI})$ and cetane number $(\mathrm{CN})$}

The CI was computed by the correlation reported by Krisnangkura, 1986 [17], using iodine and saponification values of sample already determined.

$$
C I=46.3+(5458 / S V)-0.25(I V)
$$

where $S V$ is Saponification value; and $I V$ is Iodine value.

The Cetane number $(\mathrm{CN})$ was then obtained from a correlation as given in Equation (8) [18].

$$
C N=C I-2.6
$$

\section{Results and Discussion}

\subsection{Physico-chemical properties of soya bean oil}

The physico-chemical properties of soya bean oil were determined and presented in Table 1. The results are less than the values obtained from literature. The decreased values may be due to the fact that the commercial soya bean oil had been refined. The phosphatide and other suspended impurities have been removed during the process of refining [19] 
J. O. Osarumwense et al. / NIPES Journal of Science and Technology Research

2(3) 2020 pp. $183-190$

Table 1: Properties of soya bean oil

\begin{tabular}{lccc}
\hline \multicolumn{1}{c}{ Parameter } & Soya bean Value & Reported values in literature & References \\
\hline Density $\left(\mathrm{kgm}^{-3}\right)$ & $893 \pm 13$ & 917 & {$[19]$} \\
Viscosity $\left(\mathrm{mm}^{2} / \mathrm{s}\right) @ 40^{\circ} \mathrm{C}$ & $12.8 \pm 1.8$ & 29.37 & {$[20]$} \\
Acid Value $(\mathrm{mgKOH} / \mathrm{g})$ & $0.96 \pm 0.9$ & $2.72 \pm 0.17$ & {$[19]$} \\
& & 310 & {$[20]$} \\
Flash Point $\left({ }^{\circ} \mathrm{C}\right)$ & $219 \pm 12$ & 335 & {$[19]$} \\
Saponification Value $(\mathrm{mgKOH} / \mathrm{g})$ & & $166.5 \pm 1.5$ & {$[21]$} \\
& $154 \pm 8.3$ & 198 & {$[19]$} \\
Iodine Value $(\mathrm{g} / 100 \mathrm{~g})$ & $119 \pm 5.7$ & $120-136$ & {$[19]$} \\
FFA $(\%)$ & $0.48 \pm 0.05$ & $1.36 \pm 0.08$ & {$[19]$} \\
\hline
\end{tabular}

\subsection{Production of biodiesel}

The production of biodiesel from soya bean oil was achieved in a single run within the 60 minutes of operation, and the separation of the biodiesel-glycerol mixture into two phases started almost immediately the reaction was stopped. As a result of this success in the production process, $94 \%$ biodiesel yield was achieved. The high yield was due to the low value of FFA $(<0.5)$ of soya bean oil, and the high reactivity nature of sodium hydroxide as the catalyst in transesterification reaction [18].

Table 2: Physico-chemical properties of biodiesel

\begin{tabular}{lccc}
\hline \multirow{2}{*}{\multicolumn{1}{c}{ Parameter }} & Biodiesel & \multicolumn{2}{c}{ Standard values } \\
\cline { 3 - 4 } & Values & ASTM D6751 & EN 14214 \\
\hline Flash Point $\left({ }^{\circ} \mathrm{C}\right)$ & $132 \pm 4.1$ & $130(\mathrm{~min})$ & $101(\mathrm{~min})$ \\
Cloud Point $\left({ }^{\circ} \mathrm{C}\right)$ & $10.4 \pm 1.8$ & -3 to 10 & - \\
Pour Point $\left({ }^{\circ} \mathrm{C}\right)$ & $13.2 \pm 2.1$ & -5 to 15 & - \\
Saponification Value $(\mathrm{mgKOH} / \mathrm{g})$ & $142.5 \pm 8.6$ & - & - \\
Acid Value $(\mathrm{mgKOH} / \mathrm{g})$ & $0.3 \pm 0.6$ & $0.8(\max )$ & $0.5(\mathrm{max})$ \\
Density @ $30^{\circ} \mathrm{C}\left(\mathrm{kgm}{ }^{-3}\right)$ & $877 \pm 23.4$ & - & - \\
Iodine Value $(\mathrm{g} / 100 \mathrm{~g})$ & $118 \pm 8.7$ & - & $115(\mathrm{~min})$ \\
Cetane number & $52.5 \pm 3.2$ & $48-65$ & $51(\mathrm{~min})$ \\
FFA $(\%)$ & $0.15 \pm 0.04$ & - & - \\
Viscosity $\left(\mathrm{mm}^{2} / \mathrm{s}\right) @ 40^{\circ} \mathrm{C}$ & $4.30 \pm 1.3$ & $1.9-6.0$ & $3.5-5.0$ \\
\hline
\end{tabular}




\subsection{Physico-chemical characteristics of biodiesel}

The physico-chemical properties analysis was conducted on the produced biodiesel and compared with standard values as presented in Table 2 . The viscosity obtained in this study was $4.30 \mathrm{~mm}^{2} / \mathrm{s}$. The result agrees with the standard ranges of ASTM 6751 and EN14214. The viscosity property is one of the reasons why transesterification is carried out on vegetable oil to produce biodiesel [22]. Figure 1 shows the comparison of the viscosity values for soya bean oil and the soya bean oil-based biodiesel. Viscosity is a measure of the resistance of fuel to deformation gradually by shear stress. Usually, it is measured as the ratio of the absolute viscosity to the density of fluid known as Kinematic viscosity. It has been reported in literature that, lubricity of a fuel is somehow related to its viscosity [23]. Fuel with low viscosity do not seems to provide appropriate lubrication to the injection pumps; this often leads to increase in wear and seepage in the engine. On the other hand, fuel with high viscosity gives incomplete combustion, increased exhaust emissions thereby causing choking of the injections, forming droplets of larger diameter on the injector in the engine. [23, 24]. The flash point obtained in this study was $132^{\circ} \mathrm{C}$. Flash point is the minimum temperature at which a fuel must be heated for it to ignite air -vapor mixture. This value is within the ranges specified by international standards. The high flash point result indicates that the residual methanol in the crude biodiesel was wash out during the purification process. It has been reported that a little quantity of methanol reduces the flash point of biodiesel thereby negatively affecting parts of engine [25]. The cloud and pour point obtained are $10.4^{\circ} \mathrm{C}$ and $13.2^{\circ} \mathrm{C}$ respectively. These are found to fall within standard values. The cloud point is the temperature of a liquid at which the smallest observable cluster of crystals or haziness first occurs upon cooling [13]. The haziness may be due to the separation of waxes at low temperature and as a result, viscosity of the fluid increases and its fluidity decreases. While the pour point is the temperature where the liquid becomes semi solid and loses its flow properties. The presence of solidified waxes thickening the fuel, and clogs filters and injectors in the engine [14]. The cetane number obtained in this study is within specified standards. This indicates that the fuel possesses good fuel ignition property. This means that this biodiesel offers easier starting operation in automobile engines [6]. The acid value of this biodiesel was lower than the standard values. The low value means the biodiesel has very good storage stability. The FFA value obtained $(0.15 \%)$ shows that the biodiesel has a good cleaning property and will have fewer tendencies to cause rupture and degradation in engine hose [16]. Iodine value is a measure of the degree of un-saturation in vegetable oil, and the higher the iodine value, the higher the unsaturated fatty acid [26]. The effect of unsaturated fatty acid in biodiesel is that the heating of unsaturated fatty acids brings about the polymerization of glycerides which may lead to the formation of deposits [27]. The iodine value for soya bean oil-based biodiesel was found to be 118 $\mathrm{g} / 100 \mathrm{~g}$. This is fell within the standard specification (115 minimum). This is an indication that the volume of unsaturated fatty chains in the biodiesel is within the standards range.

\subsection{Comparison of properties of soya bean oil and soya bean oil-based biodiesel}

Figure 1 shows the comparison of some properties of soya bean oil and the biodiesel produced via transesterification reaction. The transesterification of soya bean oil has significantly reduced the viscosity, acid value and flash point of the oil by $66.4 \%, 71.6 \%$ and $55.7 \%$ respectively. This conforms to a previous study where it was reported that transesterification of vegetable oil reduces the molecular mass, the viscosity and improve the volatility of vegetable oils to appropriate range suitable for the usage of diesel engines [11]. It has been reported that the higher the viscosity of biodiesel fuel, the greater is the tendency for the fuel to form deposits in the engine while a low viscosity may lead to excessive internal pump leakage [11,28]. 


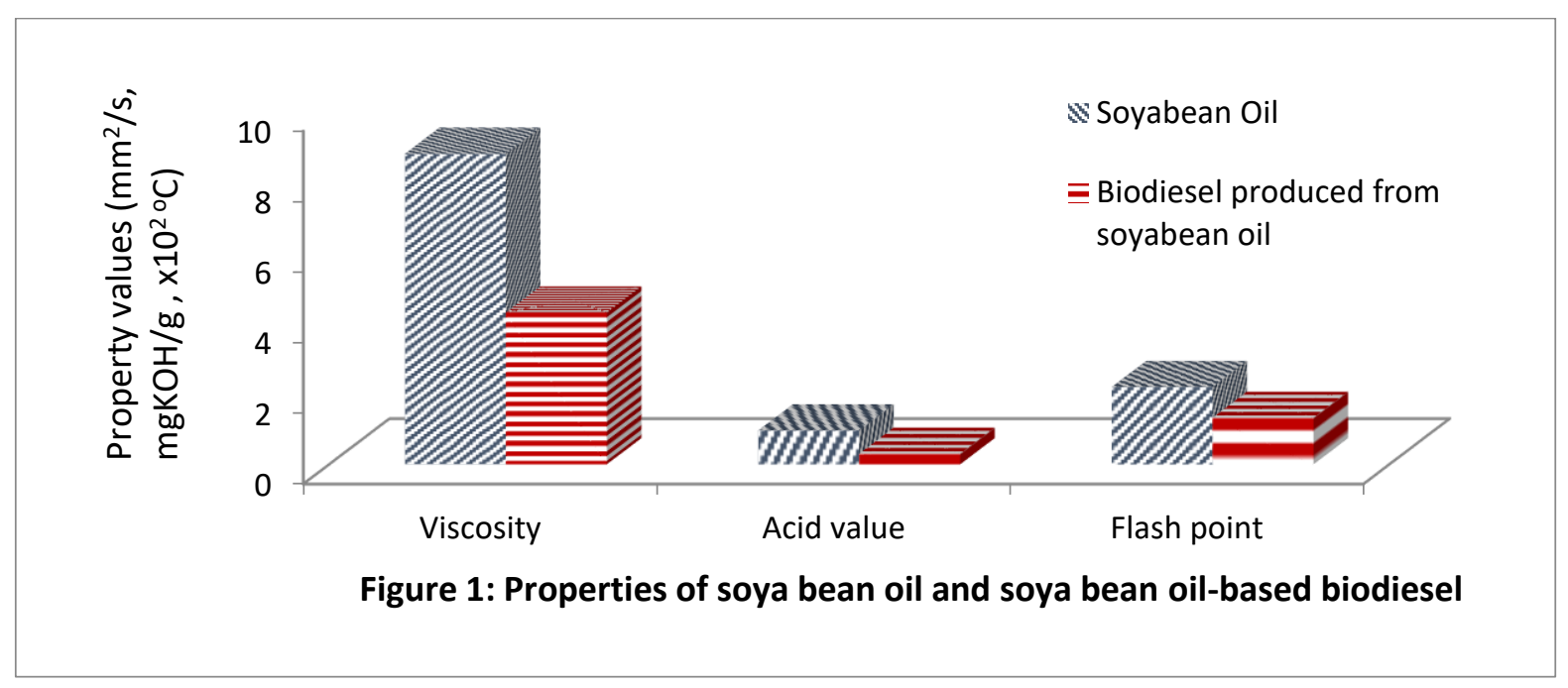

\section{Conclusion}

The transesterification of soya bean oil has reduced most of the properties of soya bean oil significantly. The values of viscosity, acid value and flash point of the oil were reduced by $66.4 \%$, $71.6 \%$ and $55.7 \%$ respectively. The density, cetane number, pour point, iodine value, and cloud point of the biodiesel fell within the specified international standard. Because of the renewability of soya bean oil, the biodiesel produce from this source can be used as a viable replacement for the fossil fuel diesel; in order to combat the ever increasing toxic pollution of the environment.

\section{Nomenclature}

$\begin{array}{ll}B V & \text { Volume of sodium thiosulphate used for blank }\left(\mathrm{cm}^{3}\right) \\ C F & \text { Conversion coefficient } \\ D & \text { Density of sample } \\ M & \text { Mass of sample }(\mathrm{g}) \\ M_{B} & \text { Mass of dried biodiesel }(\mathrm{g}) \\ M_{\text {oil }} & \text { Mass of oil used }(\mathrm{g}) \\ N_{K O H} & \text { Concentration of } \mathrm{KOH}(\mathrm{N}) \\ N & \text { Actual concentration of } \mathrm{HCl} \text { used }(\mathrm{M}) \\ S V & \text { Saponification value }(\mathrm{mgKOH} / \mathrm{g}) \\ T & \text { Titre volume }\left(\mathrm{cm}^{3}\right) \\ T V & \text { Volume of sodium thiosulphate used for sample }\left(\mathrm{cm}^{3}\right) \\ V_{1} & \text { Titre volume of the HCl used for sample }\left(\mathrm{cm}^{3}\right) \\ V_{O} & \text { Titre volume of HCl used for blank }\left(\mathrm{cm}^{3}\right) \\ V_{L} & \text { Volume of the sample }\left(\mathrm{cm}^{3}\right) \\ w_{1} & \text { Mass of bottle and sample }(\mathrm{g}) \\ w_{0} & \text { Mass of bottle only }(\mathrm{g})\end{array}$

\section{References}

[1] Barnwal B. K. and Sharma M. P. (2005). Prospects of biodiesel production from vegetables oils in India. Renewable and Sustainable Energy Reviews, 9:363-378.

[2] Bamgboye, A. I. and Hansen, A. C. (2008). Prediction of cetane number of biodiesel fuel from the fatty acid methyl ester (FAME) composition. International Agrophysics Journal, 22:21-29.

[3] Abrakasa S. and Onojalce, M. C. (2012). Petroleum Related Environmental Pollution in Nigeria: Potential Ways for Constraints. International Journal of Environmental and Bioenergy, 2(1): 53-61.

[4] Lin L., Cunshan, Z., Vittayapadung, S., Xiangqian, S. and Mingdong, D. (2011). Opportunities and challenges for biodiesel fuel. Applied Energy, 88(4): 1020-1031.

[5] Khan and Yamsaengsung, (2011). Review of wastewater treatment methods and MBR technology for application in biodiesel plants. TIChE International Conference, Hatyai, Sonkhla. Thailand, 1-5. 
[6] Aleme, H. G. and Barbeira, P. J. S. (2012). Determination of flash point and cetane index in diesel using distillation curves and multivariate calibration. Fuel, 102: 129-134

[7] Van-Gerpen, J., Shanks, B., Pruszko, R., Clements, D. and Knothe, G. (2004). Biodiesel Analytical Methods.

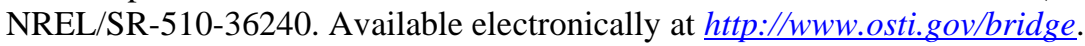

[8] Enweremadu, C. C. and Alamu, O. J. (2009). Development and characterization of Biodiesel from Shea nut butter. International Agrophysics Journal, 24: 29-34.

[9] Osarumwense, J. O., Oti, E. O. and Erhaghewu, J. E. (2017). Evaluation of African oil bean (Pentaclethra Macrophylla benth) seed oil as potential feedstock for biodiesel production. Nigerian Research Journal of Engineering and Environmental Sciences, 2(1): 65-73.

[10] Akpan, U. G., Jimoh, A. and Mohammed, A. D. (2006). Extraction, characterization and modification of castor seed oil. Leonardo Journal of Sciences, 8: 43-52.

[11] Aworanti, O. A., Agarry, S. E. and Ajani, A. O. (2012). A Laboratory Study of the Effect of Temperature on Densities and Viscosities of Binary and Ternary Blends of Soybean Oil, Soy Biodiesel and Petroleum Diesel Oil. Advances in Chemical Engineering and Science, 2: 444-452.

[12 Nita I. and Geaca S. (2012). Study of density and viscosity for ternary mixtures biodiesel, diesel fuel, and bioalcohols. Ovidius University Annals of Chemistry, 23(1): 58-62

[13] Eyankware, E. O., Ulakpa, W. C. and Eyankware, M. O. (2016). Determination of Cloud and Pour Point of Crude Oil with Reference to Crude Transportation. International Journal of Science and Healthcare Research, 1(3): 2028.

[14] Akhil, A. G., Mohammed, A. K. P., Akhilesh, S., Muhammad C. A., Salman K. and Rajesh K. (2017). Determination of Cloud and Pour Point of Various Petroleum Products. International Referred Journal of Engineering and Science, 6(9): 1-4

[15] Wu, X. and Leung, D. Y. C. (2011). Optimization of biodiesel production from camelina oil using orthogonal experiment. Applied Energy, 88(11): 3615-3624.

[16] Aransiola, E. F., Daramola, M. O., Ojumu, T. V., Aremu, M. O. and Layokun, S. K., (2013). Homogeneously Catalyzed Transesterification of Nigerian Jatropha enreas Oil into Biodiesel: A Kinetic Study. Modern Research in Catalysis. 2: 83-89

[17] Krisnangkura K. (1986). A simple method for estimation of cetane index of vegetable oil methyl esters. Journal of the American Oil Chemists Society, 63(4): 552-553.

[18] Ejeh and Aderemi, (2014), Production of Biodiesel from Shea Butter Oil using Homogeneous Catalysts. Leonardo Journal of Sciences, 1-14

[19] Abitogun, A., Jide, A., Aranwande, O. and Omosheyin, A. (2008). Effect of phosphoric acid on physico-chemical parameters of soya bean oil. The Internet Journal of Nutrition and Wellness, 8(2): 1-5.

[20] Ozioko, F. U. (2012). Extraction and characterization of soya bean oilbased bio-lubricant. AU Journal of Technology, 15(4): 260-264.

[21] Khatoon, S., Rangan, R. G. R. and Krishna, A. G. G. (2010). Physico-chemical characteristics and composition of Indian soya bean and the recovery of phytosteroids. Journal of American Chemist's Society, 87:321-326

[22] Ayetor, G. K., Sunnu, A. and Parbey, J. (2015). Effect of biodiesel production parameters on viscosity and yield of methyl esters: Jatropha curcas, Elaeis guineensis and Cocos nucifera. Alexandria Engineering Journal, 54(4): $1285-1290$

[23] Liliwirianis N., Musa, N. L. W., Zain, W. Z. W. M., Kassim, J. and Karim, S. A. (2011). Preliminary studies on phytochemical screening of Ulam and fruit from Malaysia. E-Journal of Chemistry, 8(S1): S285-S288.

[24] Raja, A. G. K., Furqan, A. K. and Muhammad, A. K. (2011). "Impact of Training and Development on Organizational Performance”. Global Journal of Management and Business Research. 11(7): 62-68.

[25] Berrios, M., and Skelton, R. L. (2008). Comparison of purification methods for biodiesel. Chemical Engineering Journal, 144(3): 459-465.

[26] Panigrahi, N., Das, A. M. and Hota, K. (2017). Production of biodiesel from non-edible tree-borne oils and its fuel characterization. Indian Journal of Scientific Research 15(2): 38-45.

[27] Belewu, M. A., Adekola, F. A., Adebayo, G. B., Ameen, O. N., Muhammed, N. O., Olaniyan, A. M., Adekola, O. F. and Musa, A. K. (2010). Physico-chemical characteristics of oil and Biodiesel from Nigeria and Indian Jatropha Curcas seeds. International Journal of Biological and Chemical Sciences, 4(2): 524-529.

[28] Babu, P. S. and Venkata, R. M. (2012). Significance of biodiesel use as I.C. engine fuels. International Journal of Advanced Engineering Research and Studies, 1(2): 40-43. 